\title{
Genetic and pharmacologic inhibition of Tpl2 kinase is protective in a mouse model of ventilator-induced lung injury
}

Evangelos Kaniaris ${ }^{1 \dagger}$, Katerina Vaporidi ${ }^{{ }^{*}+}$, Eleni Vergadi ${ }^{1}$, Emmanuel E Theodorakis ${ }^{1}$, Eumorfia Kondili ${ }^{1}$, Eleni Lagoudaki ${ }^{2}$, Christos Tsatsanis $^{3}$ and Dimitris Georgopoulos ${ }^{1}$

* Correspondence:

vaporidi@med.uoc.gr

†Equal contributors

${ }^{1}$ Department of Intensive Care

Medicine, Experimental Intensive

Care Medicine Laboratory,

University of Crete, School of

Medicine, Heraklio, Crete 71003,

Greece

Full list of author information is

available at the end of the article

\begin{abstract}
Background: Mechanical stress induced by injurious ventilation leads to pro-inflammatory cytokine production and lung injury. The extracellular-signalregulated-kinase, ERK $1 / 2$, participates in the signaling pathways activated upon mechanical stress in the lungs to promote the inflammatory response. Tumor progression locus 2 (Tp/2) is a MAP3kinase that activates ERK1/2 upon cytokine or TLR signaling, to induce pro-inflammatory cytokine production. The role of Tpl2 in lung inflammation, and specifically in the one caused by mechanical stress has not been investigated. The aim of the study was to examine if genetic or pharmacologic inhibition of Tpl2 could ameliorate ventilator-induced lung injury.
\end{abstract}

Methods: Adult male wild-type and Tpl2-deficient mice were ventilated with normal or high tidal volume for $4 \mathrm{~h}$. Additional wild-type mice were treated with a Tpl2 inhibitor either before or $30 \mathrm{~min}$ after initiation of high tidal ventilation. Non-ventilated mice of both genotypes served as controls. The development of lung injury was evaluated by measuring lung mechanics, arterial blood gases, concentrations of proteins, IL-6, and MIP-2 in bronchoalveolar lavage fluid (BALF) and by lung histology. Data were compared by Kruskal-Wallis non-parametric test and significance was defined as $p<0.05$.

Results: Mechanical ventilation with normal tidal volume induced a mild increase of IL-6 in BALF in both strains. High tidal volume ventilation induced lung injury in wild-type mice, characterized by decreased lung compliance, increased concentrations of proteins, IL-6 and MIP-2 in BALF, and inflammatory cell infiltration on histology. All indices of lung injury were ameliorated in Tpl2-deficient mice. Wild-type mice treated with the Tpl2 inhibitor, either prior of after the initiation of high tidal volume ventilation were protected from the development of lung injury, as indicated by preserved lung compliance and lower BALF concentrations of proteins and IL-6, than similarly ventilated, untreated wild-type mice.

Conclusions: Genetic and pharmacologic inhibition of Tpl2 is protective in a mouse model of ventilator-induced lung injury, ameliorating both high-permeability pulmonary edema and lung inflammation.

Keywords: Tumor progression locus 2; Tpl2 inhibitor; Extracellular signal-regulated kinase; Lung injury; Mechanical stress; Mechanical ventilation

\section{Springer}

(c) 2014 Kaniaris et al.; licensee Springer. This is an Open Access article distributed under the terms of the Creative Commons Attribution License (http://creativecommons.org/licenses/by/2.0), which permits unrestricted use, distribution, and reproduction in any medium, provided the original work is properly credited. 


\section{Background}

Ventilator-induced lung injury (VILI) is a well-recognized complication of mechanical ventilation. The mechanical stress caused by a relatively high tidal volume, applied on an injured lung causes an abnormally high distortion (strain) of lung cells. The cellular responses to increased stress and strain result in alveolar barrier disruption and activation of inflammation, therefore inducing or exacerbating acute lung injury (ALI).

Several cell types mediate the effects of strain induced by mechanical ventilation. Increased strain, either in vivo or in vitro, impairs barrier properties of alveolar epithelial and endothelial cells [1-3]. Moreover, both alveolar epithelial and endothelial cells have been shown to produce pro-inflammatory cytokines when subjected to deformation $[4,5]$. Alveolar macrophages are also activated by cyclic stretch [6], and have been shown to mediate not only inflammation, but also barrier dysfunction [6-8].

The extracellular signal-regulated kinase $1 / 2$ (ERK1/2) is a member of the mitogenactivated serine/threonine kinase (MAPK) family, which also includes the kinases p38 and C-Jun N-terminal Kinase (JNK). MAPK are highly conserved enzymes regulating a vast array of cellular functions, including cell survival, proliferation, and differentiation, as well as inflammation and stress responses $[9,10]$. Several cells respond to mechanical forces by activating MAPK pathways [11]. Mechanical stress has been shown to stimulate ERK1/2 in pulmonary epithelial cells [12] and endothelial cells [13]. ERK1/2 activation upon cyclic stretch has been reported in human bronchial epithelial cells [4] and primary rat alveolar epithelial cells [14]. In an in vitro model of VILI, cyclic stretch-induced interleukin-8 production from lung epithelial cells was reduced by ERK1/2 inhibition [4]. In vivo, bleomycin plus ventilation-induced lung fibrosis was attenuated in mice with pharmacologic inhibition of ERK1/2 [15].

Given the important role of ERK1/2 in cell proliferation, ERK1/2 inhibitors have been investigated as candidate targets in cancer and rheumatoid arthritis [16-18]. Nevertheless, defective ERK1/2 signaling has been associated with autoimmunity [19] raising concerns for the use of ERK1/2 inhibition in inflammatory diseases, emphasizing the need for more selective therapeutic targets [18].

Activation of each of the three MAPKs is controlled by several MAP3Ks ensuring the specificity of signaling responses. Tumor progression locus 2 (Tpl2) is a MAP3kinase that phosphorylates and activates the extracellular signal-regulated kinase (ERK1/2) [20-22]. Tpl2 was originally identified as a proto-oncogene, but is now recognized to play an important role in regulating ERK1/2 signaling in multiple cell types, including T-cells, macrophages, and epithelial cells [22-26]. In vitro studies using Tpl2 overexpressing cells have shown that Tpl2 activates ERK, JNK, p38, and the transcription factors NFAT (nuclear factor of activated T cells) and NF-kB [23,27]. In vivo, expression of a constitutively active form of $\mathrm{Tpl} 2$ under the control of a $\mathrm{T}$ cell-specific promoter in mice resulted in development of thymic lymphomas [21]. On the contrary, Tpl2deficent $\left(\mathrm{Tpl} 2^{-/-}\right)$mice remain healthy throughout their normal life span [28]. Studies on $\mathrm{Tpl} 2^{-/}$mice have proven that $\mathrm{Tpl} 2$ participates in signal transduction of TLR, T-cell receptors, G protein-coupled receptors, tumor necrosis factor (TNF), and CD-40 $[25,28-30]$. In these studies, the anti-inflammatory effects of Tpl2 ablation were recognized. $\mathrm{Tpl} 2^{-/}$macrophages produce less inflammatory mediators upon lipopolysacharite (LPS) stimulation [29], and $\mathrm{Tpl} 2^{-/}$mice are resistant to LPS-induced shock [28]. In a model of acute pancreatitis, lung inflammation was less in $\mathrm{Tpl} 2^{-1}$ mice [31], and in a 
model of experimental colitis, $\mathrm{Tpl} 2^{-1-}$ mice and mice treated with a Tpl2 inhibitor had less bowel inflammation [32].

The present study examined the hypothesis that genetic and pharmacologic inhibition of Tpl2 can ameliorate VILI. We first compared naïve wild type (WT) and Tpl2 $2^{-1-}$ mice, as well as WT and $\mathrm{Tpl}^{-/-}$mice ventilated for $4 \mathrm{~h}$ with normal tidal volume (VT), to exclude any unexpected effect of Tpl2 deficiency on lung mechanics, response to anesthesia, or normal-VT ventilation. We then subjected WT and $\mathrm{Tpl} 2^{-/}$mice to mechanical ventilation with high VT, under conditions previously shown to induce severe VILI in WT mice [33]. Finally, we examined the effect of pharmacologic inhibition of Tpl2 in WT mice subjected to mechanical ventilation with high VT, when given as a pretreatment, before the initiation of high VT, and, in a more clinically relevant approach, given after initiation of high VT ventilation.

\section{Methods}

\section{Animal experiments}

We studied 12 groups of mice, a total of 58 male C57BL6 (WT) and 44 Tpl2 ${ }^{-/-}$mice on C57Bl6 background [28] at 8 to 10 weeks of age (25- to $30-\mathrm{g}$ weight). The experimental groups and number of mice in each group are presented in Table 1 , and the experimental procedure is shown in Figure 1. Mice were obtained from the Foundation of Research and Technology Institute Animal Facility. All experiments were approved by the Research Animal Care Committee of University of Crete Medical School and Heraklion Prefecture Veterinary Authority. All experiments were performed at the experimental Intensive Care Medicine laboratory at the Medical School of the University of Crete.

The effects of mechanical ventilation on the development of lung injury were studied in WT and $\mathrm{Tpl}^{2 /-}$ mice ventilated with either normal or high tidal volume (VT), as detailed below, and described previously [33]. Mice were anesthetized with intraperitoneal (i.p.) injection of ketamine $100 \mathrm{mcg} / \mathrm{g}$ and fentanyl $0.12 \mathrm{mcg} / \mathrm{g}$ [33], tracheostomized, and ventilated using SAP830 ventilator (IITC Life Science, Woodland Hills, CA, USA). Ventilation settings for normal VT were $\mathrm{VT}=10 \mathrm{ml} / \mathrm{kg}$ resulting in peak inspiratory pressure (PIP) $=9 \pm 0.5 \mathrm{cmH}_{2} \mathrm{O}$, positive end-expiratory pressure PEEP $=1.5 \mathrm{cmH}_{2} \mathrm{O}$, respiratory rate $(\mathrm{RR})=130 \mathrm{breaths} / \mathrm{min}$, with recruitment maneuvers performed every $30 \mathrm{~min}$. For high VT, ventilation settings were changed from normal VT after $30 \mathrm{~min}$

Table 1 Experimental groups

\begin{tabular}{lcr}
\hline Strain treatment & \multicolumn{2}{c}{ Sample $(\mathbf{N})$} \\
\cline { 2 - 3 } & WT & Tpl2 ${ }^{-/-}$ \\
\hline Control-PV curve and sample collection & 10 & 10 \\
Normal VT ventilation & 8 & 8 \\
High VT ventilation & 8 & 8 \\
High VT ventilation + Tpl2 inhibitor pretreatment & 5 \\
High VT ventilation + Tpl2 inhibitor posttreatment & 5 \\
Control-no ventilation (ERK1/2 phosphorylation) & 6 & 6 \\
Normal VT 60 min (ERK1/2 phosphorylation) & 4 & 4 \\
Normal VT 30 min + High VT 30 min (ERK1/2 phosphorylation) & 8 & 8 \\
Normal VT 30 min + High VT 30 min (ERK1/2 phosphorylation) + Tpl2 inhibitor pretreatment & 4 & \\
\hline
\end{tabular}




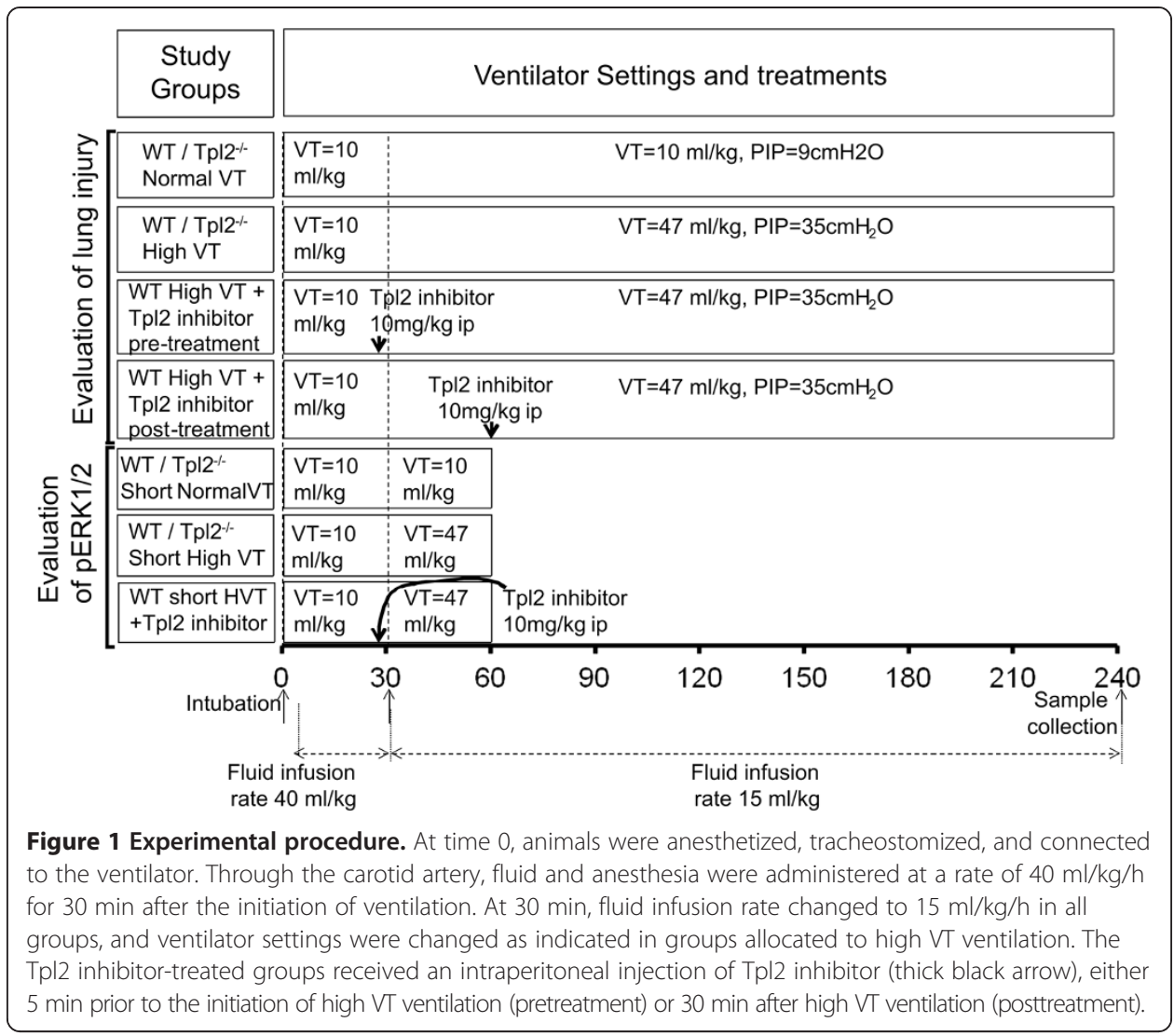

of hemodynamic stabilization, to high $\mathrm{VT}=47 \pm 2 \mathrm{ml} / \mathrm{kg}$, targeted to a PIP $=35 \pm 0.5$ $\mathrm{cmH}_{2} \mathrm{O}, \mathrm{RR}=60$ breaths $/ \mathrm{min}, \mathrm{PEEP}=1.5 \mathrm{cmH}_{2} \mathrm{O}$, without recruitment maneuvers. Fraction of inspired oxygen $\left(\mathrm{FiO}_{2}\right)$ was $30 \%$ in all experiments, and inhaled carbon dioxide $\left(\mathrm{CO}_{2}\right)$ was added in high VT groups to prevent hypocapnia. Arterial blood pressure, PIP, PEEP, and VT were monitored throughout the study. At the end of the 240-min experiment, blood was collected from the arterial line for blood gas analysis, followed by inspiratory pressure volume curve, bronchoalveolar lavage fluid (BALF) and tissue collection. For histological evaluation, lungs from mice not subjected to BALF collection were inflated with $4 \%$ paraformaldehyde at a transpulmonary pressure of $25 \mathrm{cmH}_{2} \mathrm{O}$.

The possible protective effects of pharmacologic Tpl2 inhibition were studied in WT mice ventilated with high VT as described above, and treated with a Tpl2 inhibitor (Calbiochem \#616404, USA) $10 \mathrm{mg} / \mathrm{kg}, 20-\mu \mathrm{l}$ DMSO in a $0.2-\mathrm{ml}$ normal saline given as a single i.p. injection as per manufacturer's instructions, and previous reports [34]. Two groups of WT mice treated with Tpl2 inhibitor were studied: the pretreatment group, in which the inhibitor was given 5 min prior to the initiation of high VT ventilation, and the posttreatment group, in which the inhibitor was given $30 \mathrm{~min}$ after high VT ventilation.

As controls served WT and $\mathrm{Tpl} 2^{-/-}$mice ventilated briefly (approximately $1 \mathrm{~min}$ ), until paralyzed, to obtain an inspiratory pressure volume curve and subsequently BALF and tissue samples. 
The activation of ERK1/2 induced by mechanical ventilation, which is known to occur even after very brief periods of ventilation $[14,15]$ was studied in WT and $\mathrm{Tpl} 2^{-/}$mice in the same study groups, but total ventilation time was limited to $60 \mathrm{~min}$. Due to the rapid activation of ERK1/2 upon mechanical ventilation different controls were required for this experiment. Specifically, as controls served mice of both genotypes not subjected to mechanical ventilation, euthanized with pentobarbital. In these experiments, only BALF cells and lungs were collected.

\section{Evaluation of lung injury}

Ventilator-induced lung injury is characterized by high-permeability pulmonary edema and inflammation. The presence of high-permeability pulmonary edema was evaluated using lung compliance, oxygenation, and BALF protein concentration. The presence of inflammation was evaluated by BALF cytokines. Lung histological evaluation also provided information on alveolar membrane integrity and presence of inflammatory cellular infiltration. As an indicator of lung compliance, we used the inspiratory capacity, defined as the volume to inflate the lungs to an airway pressure of $25 \mathrm{cmH}_{2} \mathrm{O}$ [33]. Results are expressed as percentage (\%) of control and normalized to body weight due to the differences in weight of study mice. Concentration of proteins in BALF was measured using bicinchoninic acid assay (Pierce Chemical Co, Rockford, IL, USA). The levels of the proinflammatory cytokines, interleukin-6 (IL-6), and macrophage inflammatory protein 2 (MIP-2), were measured in BALF ELISAs (R\&D Systems Inc, Minneapolis, MN, USA). Paraffin-embedded lung sections, sectioned 6- $\mu \mathrm{m}$ thick and stained with hematoxylin and eosin, were analyzed by a pathologist blinded to the treatment groups. In each group, 20 random high power fields $(\times 400)$ were scored, for five independent variables: neutrophils in alveolar spaces, neutrophils in interstitial spaces, hyaline membranes, proteinaceous debris filling the airspaces, and alveolar septal thickening, as previously described [35]. The resulting injury score is a continuous value between 0 and 1 .

\section{Evaluation of ERK1/2 phosphorylation in WT and TPL2 ${ }^{-/}$mice after high VT ventilation}

Levels of ERK1/2 phosphorylation were evaluated in BALF cells by flow cytometry and in lung homogenates by Western blot. BALF cells were immediately fixed in $1.5 \%$ formaldehyde permeabilized by ice-cold methanol for $10 \mathrm{~min}$ and then washed and resuspended in PBS $\left(\mathrm{Ca}^{2+}\right.$ - and $\mathrm{Mg}^{2+}$-free) containing $0.1 \mathrm{mM}$ EDTA, 5\% FBS, and 0.05\% $\mathrm{NaN}_{3}$. BALF cells were first incubated with rabbit anti-mouse phospho-p44/42 MAPK (ERK1/2) (Thr202/Tyr204) antibody (Cell Signaling Techn, Danvers, MA, USA) for $1 \mathrm{~h}$ at $4^{\circ} \mathrm{C}$. Then, cells were incubated for $20 \mathrm{~min}$ at $4^{\circ} \mathrm{C}$ with FITC goat anti-rabbit IgG (BD Biosciences, Franklin Lakes, NJ, USA). To discriminate alveolar macrophages, cell surface staining was carried out by incubation with PerCP-Cy5.5 anti-mouse CD11c (Biolegent, San Diego, CA, USA) for $30 \mathrm{~min}$ at $4^{\circ} \mathrm{C}$. Appropriate isotype control was also used. The flow cytometry events were acquired in a MoFlo Legacy Cell Sorter (Beckman Coulter, Inc., Fullerton, CA, USA) and analyzed with the use of Summit Software (Summit Software, Inc., Fort Wayne, IN, USA). For Western blot analysis, a $100-\mu \mathrm{l}$ tissue sample was suspended in $500 \mu \mathrm{l}$ of lysis buffer containing $50 \mathrm{mM}$ Tris (pH 6.8), 2\% sodium dodecyl sulfate, 5 mM EDTA, and protease inhibitors (Complete, Boehringer, Ingelheim, Germany), homogenized, ultrasonicated, and centrifuged. A 0.1* 
volume of loading buffer (containing $0.3 \%$ bromophenol blue, $50 \%$ glycerol, $0.3 \%$ mercaptoethanol, and $50 \%[v / v]$ lysis buffer) was added. Samples were separated by sodium dodecyl sulfate-polyacrylamide gel electrophoresis and transferred to nitrocellulose membranes. Membranes were labeled with a phospho- and total ERK1/2 primary antibody (Cell Signaling Technology, Danvers, MA, USA). Washed membranes were incubated with goat anti-rabbit anti-serum conjugated with horseradish peroxidase (Amersham International, Amersham, UK). Antigen-antibody complexes on the membranes were detected by enhanced chemiluminescence (Amersham).

\section{Statistical analysis}

Data were compared by one-way ANOVA, using the Shapiro-Wilk normality test, and the Kruskal-Wallis test for non-parametric data with Dunn's multiple comparisons posttest, with SigmaStat software. For each of the parameter evaluated, the comparisons made included: comparison between similarly ventilated animals of different genotype or treatment, and of ventilated animals with their genotype-matched controls. All data in text are expressed as means \pm SD. Significance was defined as $p<0.05$.

\section{Results}

Anesthesia and mechanical ventilation for $\mathbf{2 4 0}$ min were tolerated by WT and $\mathrm{TPL2}^{-/-}$mice Blood pressure averaged $92 \pm 20 \mathrm{mmHg}$ after $30 \mathrm{~min}$ of MV and $93 \pm 23 \mathrm{mmHg}$ at the end of the experiment in WT mice, and $98 \pm 21$ and $105 \pm 24 \mathrm{mmHg}$, respectively, in $\mathrm{Tpl} 2^{-/-}$mice ( $p>0.05$ for all comparisons). All mice survived the $240 \mathrm{~min}$ of mechanical ventilation.

WT and TPL2 ${ }^{-/}$mice do not differ at baseline and after mechanical ventilation with normal VT Control WT and $\mathrm{Tpl}^{-/}$mice had no differences on histological appearance, lung compliance, and concentrations of proteins, IL-6 and MIP-2 in BALF. Similarly, after 240 min of mechanical ventilation with normal VT, WT, and $\mathrm{Tpl}^{-1-}$, the mice had no differences in all indices of lung injury studied, inspiratory capacity (Figure 2), arterial oxygen (Figure 3), and concentration of proteins (Figure 4) and IL-6 (Figure 5) in BALF. Mechanical ventilation with normal VT resulted in a similar increase in BALF IL-6 concentration in both strains.

\section{Genetic deficiency of $\mathrm{Tpl}^{-/-}$protects from high VT ventilation-induced lung injury}

Mechanical ventilation with high VT-induced high-permeability pulmonary edema that was more severe in WT than in $\mathrm{Tpl}^{-/}$mice. After $210 \mathrm{~min}$ of high VT ventilation, lung compliance decreased in WT mice to $60 \%$ of control, but not in $\mathrm{Tpl}^{-1-}$ mice $(93 \%$ of control; Figure 2). The development of pulmonary edema was associated with impaired oxygenation (Figure 3 ). $\mathrm{Tpl} 2^{-1}$ mice subjected to high VT ventilation had higher $\mathrm{PaO}_{2}$ than WT mice $(145 \pm 18$ vs. $70 \pm 13 \mathrm{mmHg}, p<0.05$, Figure 2$)$. There were no differences in $\mathrm{PaCO}_{2}, \mathrm{pH}$, and lactate between the two genotypes after high VT ventilation (data not shown). The concentration of proteins in BALF increased after high VT ventilation from baseline in WT and $\mathrm{Tpl} 2^{-1-}$ mice ( $p<0.001$ vs. corresponding controls). Yet, BALF proteins concentration was lower in $\mathrm{Tpl} 2^{-/}$than in WT mice after high VT ventilation $(1,047 \pm 385$ vs. $2,051 \pm 495 \mu \mathrm{g} / \mathrm{ml}, p<0.01$, Figure 4$)$. 


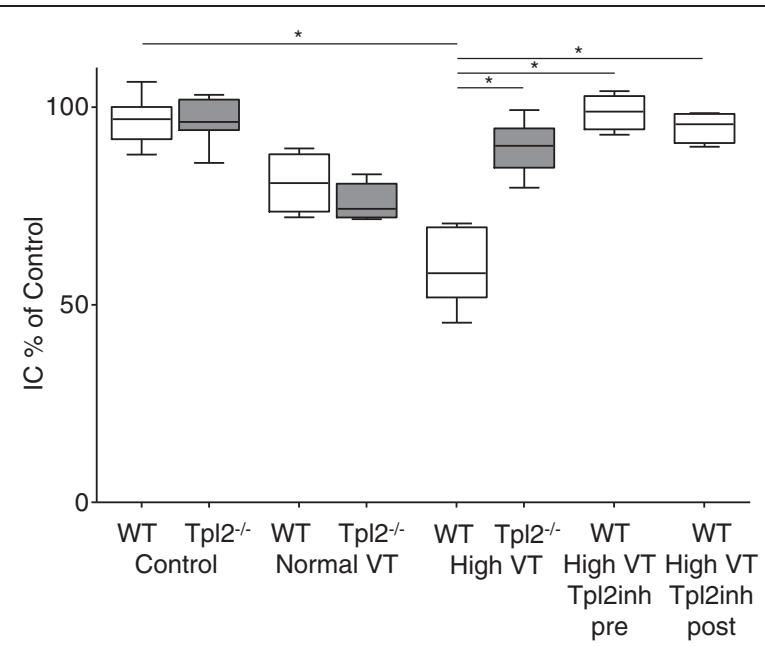

Figure $\mathbf{2}$ Lung mechanics. Inspiratory capacity, defined as the volume (in $\mathrm{ml} / \mathrm{kg}$ ) to inflate the lungs to an airway pressure of $25 \mathrm{cmH}_{2} \mathrm{O}$, expressed as percentage (\%) of control, of wild-type (WT, white boxes), and Tpl2-deficient mice (Tpl2 ${ }^{-/-}$, gray boxes) subjected only to sample collection (control, $n=8$ per group), mechanical ventilation with normal tidal volume (VT) for $240 \min$ ( $n=7$ to 9 per group), or high VT for 210 min ( $n=8$ to 9 per group), and WT mice subjected to 210 min of high VT ventilation treated with a Tpl2 inhibitor, either prior (Tpl2inh pre, $n=5$ ) or after initiation of high VT ventilation (Tpl2inh post, $n=5$ ). Wild-type mice subjected to high VT ventilation had lower inspiratory capacity compared to control WT mice, as well as compared to similarly ventilated Tpl2 ${ }^{-1-}$ mice, and WT mice treated with the Tpl2 inhibitor, ${ }^{*} p<0.01$. Data are presented in box plots, where boxes represent 25 th to 75 th percentile; line represent median and whisker represent min and max, in all figures.

Mechanical ventilation with high VT induced an inflammatory response in the lungs of mice of both genotypes, but more severe in WT than in $\mathrm{Tpl}^{-1-}$ mice. BALF concentration of IL-6 increased from control, more in WT than in $\mathrm{Tpl} 2^{-1-}$ mice, while the concentration of MIP-2 in BALF increased only in WT mice and not in $\mathrm{Tpl}^{-1-}$ mice (Figure $5 \mathrm{~A}, \mathrm{~B}$ ). In the histological examination, lungs from WT mice subjected to high VT ventilation presented severe injury with the presence of mixed inflammatory infiltrates (neutrophils and alveolar macrophages) in the interstitial and alveolar spaces, edema, and thickening of the alveolar walls, and a lung injury score of 0.7 . Lungs from $\mathrm{Tpl} 2^{-1-}$ mice subjected to



Figure 3 Oxygenation. Arterial blood gas $\mathrm{PaO}_{2}$ from wild-type (WT, white boxes), and Tpl2-deficient mice $\left(\mathrm{Tpl} 2^{-1-}\right.$, gray boxes) subjected to mechanical ventilation with normal tidal volume (VT) for $240 \mathrm{~min}$, or high VT for 210 min ( $n=6$ to 8 per group). $\mathrm{PaO}_{2}$ was lower in WT mice subjected to high VT than in similarly ventilated $\mathrm{Tp} / 2^{-/-}$mice, ${ }^{*} p<0.05$. 


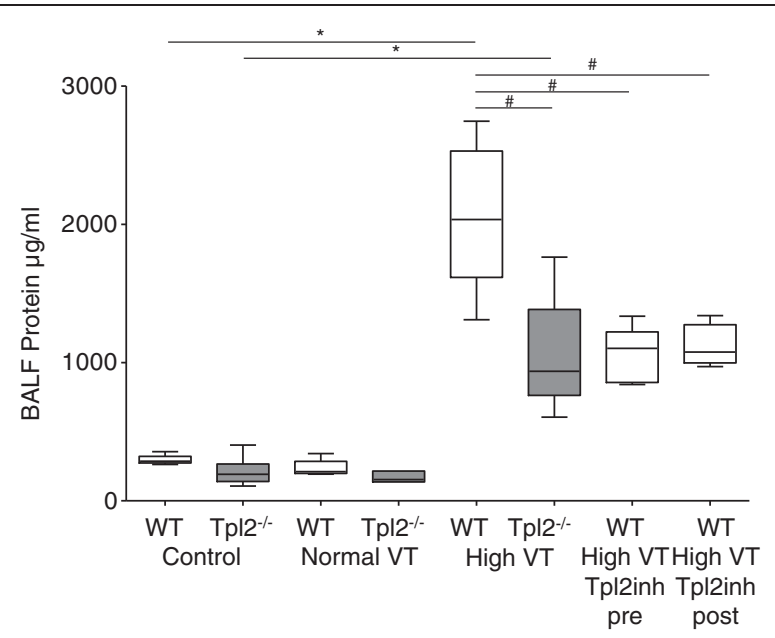

Figure 4 BALF protein. Bronchoalveolar lavage fluid (BALF) concentration of protein from wild-type (WT, white boxes), and Tpl2-deficient mice (Tpl2 ${ }^{-1-}$, gray boxes) subjected only to sample collection (control, $n=7$ to 8 per group), mechanical ventilation with normal tidal volume (VT) for $240 \mathrm{~min}$ ( $n=6$ to 8 per group), or high VT for $210 \mathrm{~min}$ ( $n=7$ to 9 per group), and WT mice subjected to $210 \mathrm{~min}$ of high VT ventilation treated with a Tpl2 inhibitor, either prior (Tpl2inh pre, $n=5$ ) or after initiation of high VT ventilation (Tpl2inh post, $n=5$ ). BALF proteins' concentration was higher in WT and Tpl2 ${ }^{-/-}$mice subjected to high $\mathrm{VT}$ ventilation, than in control WT and $\mathrm{Tpl}^{-/-}$mice, respectively, ${ }^{*} p<0.001$. BALF proteins' concentration was higher in WT mice subjected to high $V T$ ventilation than in similarly ventilated $\mathrm{Tpl} 2^{-/-}$mice, and WT mice treated with the Tpl2 inhibitor, ${ }^{\#} p<0.01$.

high VT ventilation presented only sparse, very mild inflammatory infiltrates, and a lung injury score of 0.33 (Figure 6).

\section{Pharmacologic inhibition of Tpl2 protects from high VT ventilation-induced lung injury}

The observation that Tpl2 deficiency is protective in our VILI model prompted us to examine the potential therapeutic effect of pharmacologic inhibition of Tpl2 in high VT-induced lung injury. First, we examined if pretreatment with Tpl2 inhibitor would ameliorate VILI in WT mice. When WT mice were subjected to high VT ventilation, no differences were observed between untreated mice and mice receiving an i.p. injection of DMSO in normal saline (vehicle) in any of the parameters evaluated (data not shown), and therefore, untreated mice were used as controls. Pretreatment with the Tpl2 inhibitor was effective in preventing high VT-induced decrease in lung compliance (Figure 2). Additionally, high VT-induced increase in the concentrations of protein, IL-6 and MIP-2, observed in ventilated, untreated WT mice, was less in mice pretreated with the Tpl2 inhibitor (Figures 4 and 5).

Although pretreatment was effective, such therapeutic approach is rarely feasible in clinical practice. We, therefore, tested the effects of pharmacological Tpl2 inhibition when the inhibitor was administered $30 \mathrm{~min}$ after the initiation of high VT ventilation. We found that posttreatment with the $\mathrm{Tpl} 2$ inhibitor was also effective in ameliorating indices of VILI. Lung compliance and concentrations of protein and IL-6 in BALF were similar between WT subjected to high VT ventilation and treated with the Tpl2 inhibitor either before or after initiation of high VT, and always lower than in untreated mice (Figures 2, 3, 4, and 5). Although BALF concentration of MIP-2 was similar in mice treated with the Tpl2 inhibitor before or after high VT, only the pretreated group had significantly lower MIP-2 than the untreated group (Figure 5B). 

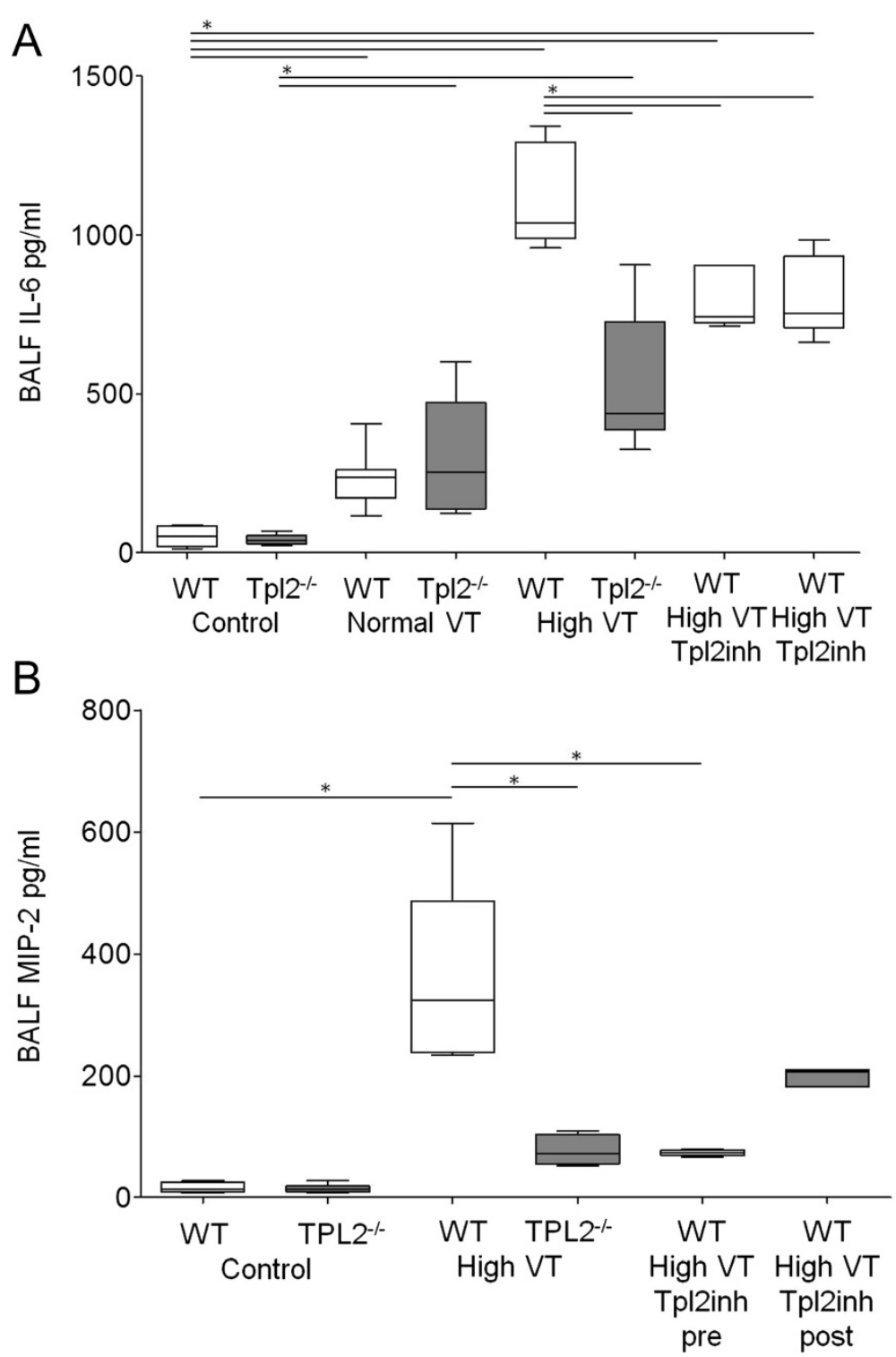

Figure 5 Bronchoalveolar lavage fluid (BALF) concentration of (A) IL-6 and (B) MIP-2, from wild-type (WT, white boxes), and Tpl2-deficient mice ( $\mathrm{Tpl}^{-1-}$, gray boxes) subjected only to sample collection (control, $\mathrm{n}=5-8$ ), mechanical ventilation with normal tidal volume for $\mathbf{2 4 0} \mathbf{~ m i n}$, or high tidal volume for $210 \mathrm{~min}(\mathrm{n}=5-7)$, and WT mice subjected to $210 \mathrm{~min}$ of high tidal volume ventilation treated with a Tpl2 inhibitor, either prior (Tpl2inh pre, $n=5)$, or after initiation of high VT ventilation (Tpl2inh post, $n=5$ ). BALF IL-6 was lower in genotype-matched control mice than in ventilated mice, ${ }^{*} p<0.05$. High tidal volume-induced increase in BALF IL- 6 was greater in WT untreated mice, than in Tpl2 ${ }^{-1-}$ mice, and WT mice treated with the Tpl2 inhibitor, ${ }^{*} p<0.05$. BALF MIP-2 concentration was higher in WT mice ventilated with high VT than in WT control mice ${ }^{*} p<0.001$. BALF MIP-2 concentration was also higher in WT mice ventilated with high VT than in similarly ventilated $\mathrm{Tp} / 2^{-1-}$ mice, and WT mice pre-treated with the Tpl2 inhibitor, ${ }^{*} p<0.001$.

High VT ventilation-induced ERK1/2 phosphorylation is decreased in alveolar macrophages of $\mathrm{Tpl} 2^{-/}$mice and WT mice treated with the Tpl2 inhibitor

It is known that ERK1/2 activation contributes to the inflammatory response induced by high VT ventilation, and that $\mathrm{Tpl} 2$ is an essential regulator of ERK1/2 activation. We therefore examined ventilation-induced activation of ERK1/2 in alveolar macrophages and total lungs homogenates from WT and $\mathrm{Tpl} 2^{-/}$mice. BALF cells from control, non- 


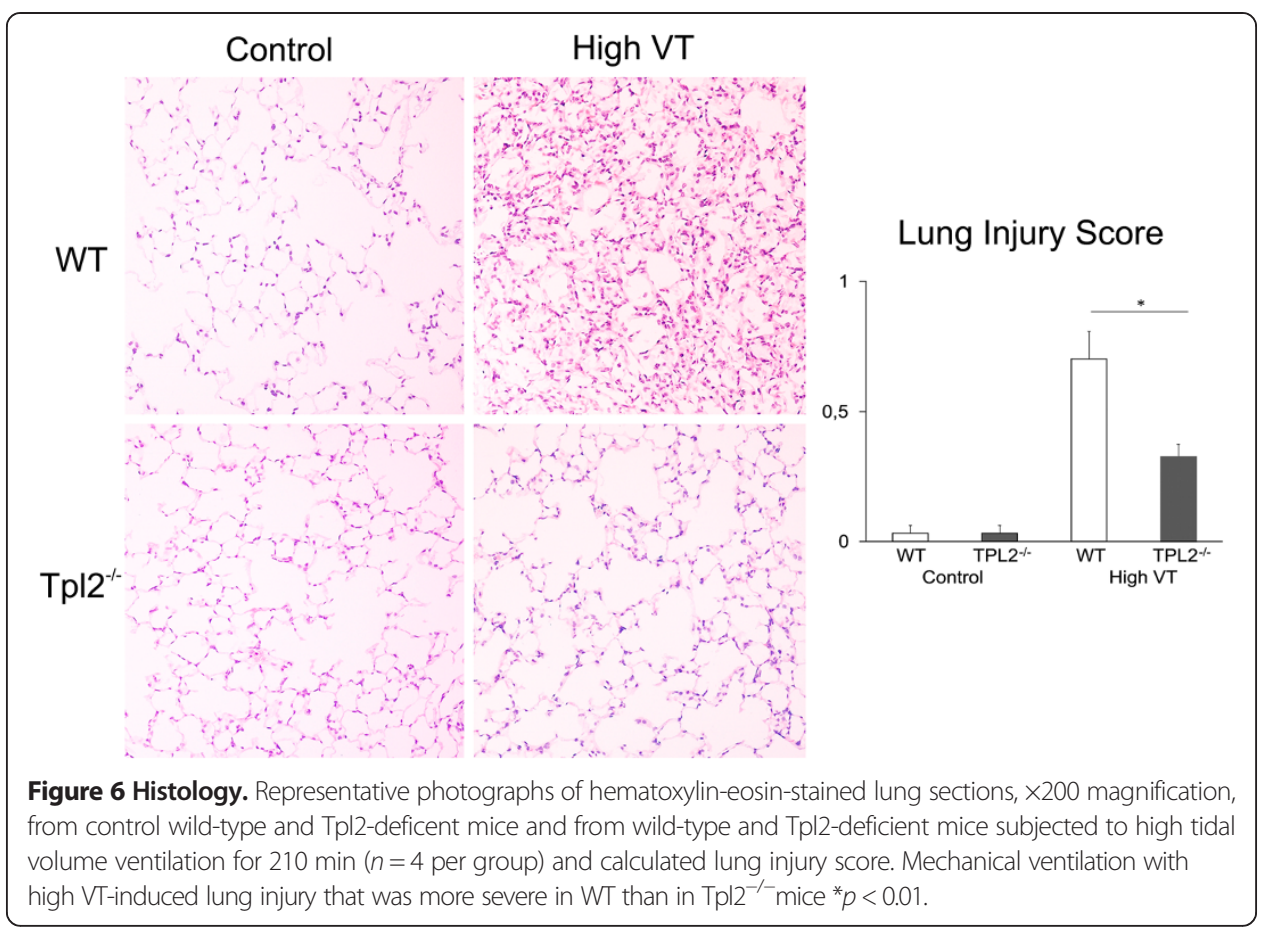

ventilated mice and from mice subjected to $60 \mathrm{~min}$ of mechanical ventilation consists of $>85 \%$ alveolar macrophages (data not shown). Mechanical ventilation with high VT but not normal VT increased ERK1/2 phoshorylation in alveolar macrophages of WT mice (Figure 7). This increase in levels of phospho-ERK1/2 after high VT ventilation was not observed in alveolar macrophages from $\mathrm{Tpl} 2^{-/-}$mice and in those from WT mice treated with the Tpl2 inhibitor. Levels of phospho-ERK1/2 were similar in lung homogenates from WT and $\mathrm{Tpl} 2^{-1-}$ mice ventilated on high VT.

\section{Discussion}

The inflammatory response and barrier dysfunction that characterize acute lung injury can be exacerbated by mechanical ventilation, and, apart from low tidal volume ventilation, no effective treatment is available yet. Identifying the intracellular signaling molecules involved in VILI is thus important for designing novel therapeutic approaches. In the present study we show that inhibition of Tpl2, a MAP3K kinase, is protective in a mouse model of VILI. Indices of high-permeability pulmonary edema and lung inflammation induced by injurious ventilation were lower in Tpl2-deficient mice than in WT ones. More importantly, this protective effect was reproduced using pharmacologic inhibition of Tpl2 in WT mice.

It is well established that injurious ventilation induces high-permeability pulmonary edema and inflammation. Studies in ARDS patients have shown that even brief periods of injurious ventilation increase BALF inflammatory mediators [36]. In mouse models, high tidal volume ventilation induces lung injury characterized by pulmonary edema with increased concentrations of proteins and cytokines in BALF and inflammatory cell infiltration and diffuse alveolar damage on histology, a picture similar to human ARDS [1]. In this study, high VT ventilation-induced lung injury in WT mice, characterized by deterioration in lung mechanics and oxygenation, increased concentration of 


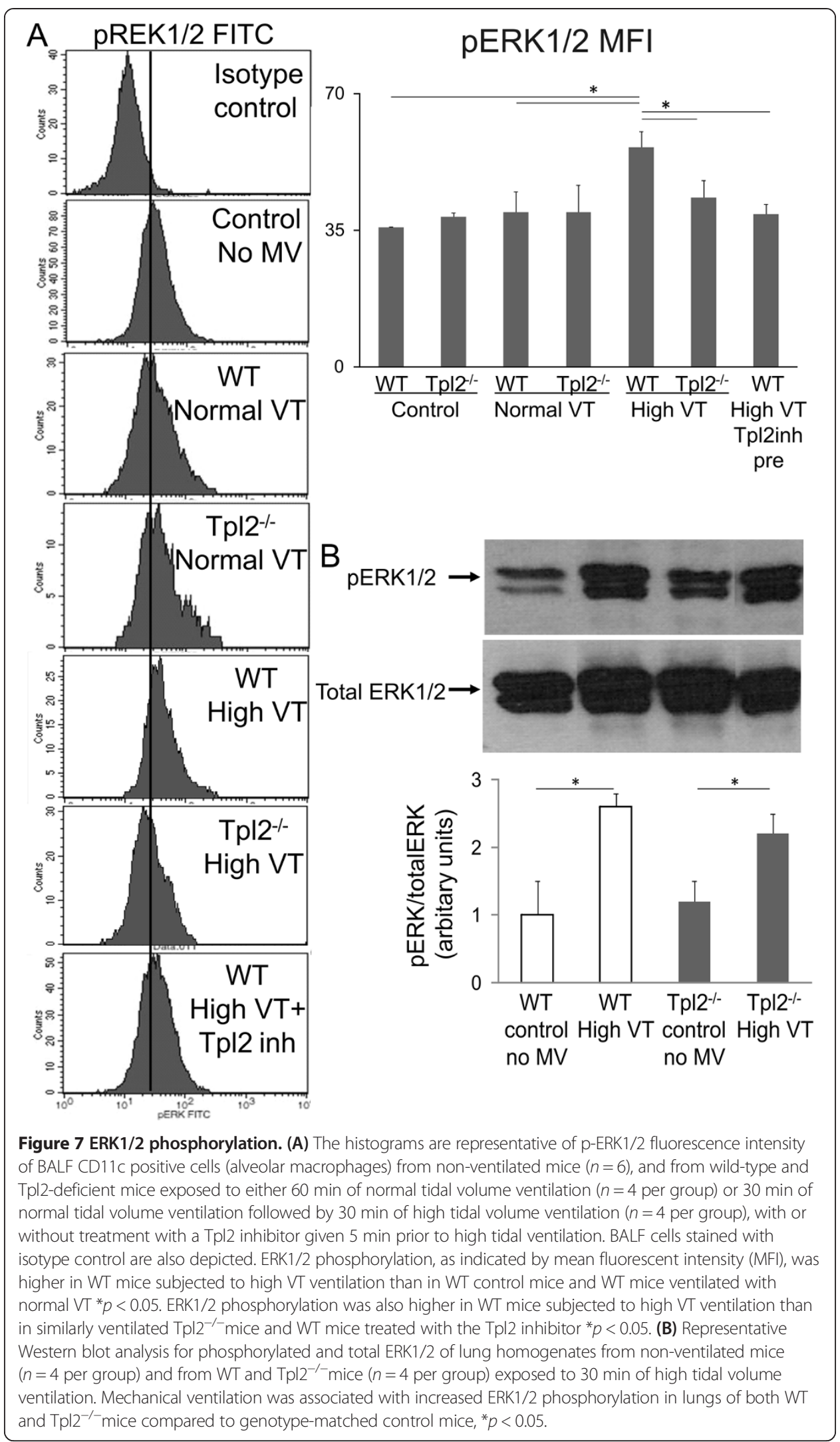


proteins and cytokines in BALF, and inflammatory cell infiltration on histology. Tpl2 deficiency was associated with less lung injury upon high VT ventilation. Specifically, Tpl2-deficient mice showed no deterioration of lung mechanics and oxygenation, less injury on histology, and lower levels of BALF proteins and cytokines than WT mice, suggesting a protective role of $\mathrm{Tpl} 2$ inhibition in VILI.

The ERK1/2 pathway is a highly conserved signaling pathway involved in fundamental cellular processes such as growth, differentiation, and survival. ERK1/2 is activated by a wide variety of receptors including G protein-coupled receptors (GPCR), tyrosine kinase receptors, TLRs, ion channels, and others $[9,10]$. Studies have shown that ERK1/2 is also involved in mechanotransduction [1], and that ERK1/2 activation by mechanical stretch contributes to the inflammatory response induced by injurious ventilation $[4,15]$.

$\mathrm{Tpl} 2$ is an essential regulator of ERK1/2 activation, mediating signals initiated by cytokine or Toll-like receptors to induce pro-inflammatory cytokine production [22,28]. In disease models, $\mathrm{Tpl} 2^{-/}$mice were initially found to be resistant to LPS/D-galactosamine-induced endotoxin shock [28]. Recent studies showed that Tpl2 deficiency was associated with reduced adipose tissue inflammation in diet-induced obesity, and reduced acetaminophen-induced liver injury [37,38]. In an experimental colitis model, pharmacologic as well as genetic inhibition of Tpl2 was found effective in reducing bowel inflammation [32]. Yet, the role of Tpl2 in inflammatory lung diseases has not been investigated. Involvement of $\mathrm{Tpl} 2$ in lung inflammation has been only indirectly demonstrated, since $\mathrm{Tpl} 2$ was found up-regulated in a proteome analysis of lung tissues from rats exposed to cigarette smoke [39], and mice lacking Tpl2 had reduced lung inflammation in a model of acute pancreatitis [31]. This study showed that Tpl2 is involved in barrier dysfunction and inflammation triggered by injurious ventilation, as inhibition of Tpl2 ameliorated lung inflammation and high-permeability pulmonary edema.

The pathway consistently shown to be impaired in the absence or inhibition of Tpl2 is the ERK1/2 pathway [25,30-32,37]. Also in this study, high tidal volume-induced ERK1/2 activation was lower in alveolar macrophages from $\mathrm{Tpl}^{-/-}$mice and from WT mice treated with the Tpl2 inhibitor than from WT untreated mice. The observation that ERK1/2 activation was similar in lung homogenates of WT and $\mathrm{Tpl} 2^{-/}$mice could be explained by the presence of other ERK1/2 activating signals, not mediated by Tpl2, such as TGF $\beta$ or other growth factors. The possible inhibition of other kinases was not examined and cannot be ruled out.

An important finding of this study is that pharmacologic inhibition of Tpl2, and not only genetic, was effective in ameliorating VILI. Systemic administration of a Tpl2 inhibitor protected from VILI, both when given as pretreatment and when given after initiation of injurious ventilation. A time point well after establishing high VT (30 min) was chosen as posttreatment, reasoning that ERK1/2 activation occurs sooner, even within 5 min after high stretch $[14,15]$, and that a deterioration of lung injury resulting in high airway pressures would be recognized by a clinician within $30 \mathrm{~min}$ and prompt therapeutic interventions. WT mice receiving the Tpl2 inhibitor after being on high VT ventilation for $30 \mathrm{~min}$ had similar lung mechanics, and BALF protein, IL- 6 and MIP-2 concentrations as $\mathrm{Tpl} 2^{-/}$mice at the end of the experiment, and lower than untreated, ventilated on high VT, WT mice. The only observed difference was that the delayed treatment with the Tpl2 inhibitor was not able to prevent the increase in BALF concentration of MIP2 induced by injurious ventilation. These findings suggest that the protective effect of $\mathrm{Tp} 2$ inhibition is quite well maintained when the inhibitor is administered after an increase in airway pressure is observed, as it would happen in clinical practice. 
The potential advantage of Tpl2 as therapeutic target over ERK1/2 is its selective activation by inflammatory stimuli with a consequent reduction in side effects. Thus, inhibition of Tpl2 will not affect activation of ERK1/2 by other agonists, like growth factors, which has been proven protective in several diseases, such as myocardial and cerebral ischemia-reperfusion injury [40,41]. Small molecule inhibitors designed to suppress Tpl2 were able to inhibit pro-inflammatory cytokine production from LPS-treated human primary macrophages [42], supporting the therapeutic potential of Tpl2 inhibition. Additionally, inhibition of $\mathrm{Tpl} 2$ has been a promising target for inflammatory diseases including inflammatory bowel disease, rheumatoid arthritis and liver disease [42-44], and Tpl2 inhibitors are among the ones to be tested in clinical trials [18].

Of course the potential adverse effects of $\mathrm{Tpl} 2$ inhibition have been evaluated neither in clinical practice nor under experimental conditions. Although $\mathrm{Tpl} 2^{-/-}$mice appear to be prone to chemically induced carcinogenesis in several animal models [22], they do not develop spontaneous cancers, and the clinical importance of Tpl2-deficiency-mediated carcinogenesis in acute inflammatory conditions, such as VILI is probably small; as such treatments would be given for only brief periods of time. Data on toxicity of Tpl2 inhibitors are lacking, but an inhibitor of MEK1/2 (mitogen-activated protein kinase kinase), a kinase that is upstream of ERK1/2 in the Raf-MEK-ERK pathway, has been investigated in phase I and phase II clinical trials in patients with advanced malignancies and proved to have a good safety profile [45-48]. A more important concern of $\mathrm{Tpl} 2$ inhibition is the potential immune suppression. Indeed, Tpl2 ablation ameliorated macrophages response to LPS [28,49], increased susceptibility of mice to Listeria monocytogenes infection [50], and decreased clearance of Toxoplasma gondii [51]. It is possible that Tpl2 inhibition could adversely affect critically ill patients with ongoing infection. This is a common limitation of all anti-inflammatory therapeutic interventions, such as corticosteroids in ALI-VILI.

In this study, we use our established model of aseptic, 'one-hit' VILI [33], to clarify the role of Tpl2. This 'one-hit' model is widely used in studies to investigate the pathogenesis of VILI. Using this model, we were able to confirm that inhibition of Tpl2 ameliorates indices of high-permeability pulmonary edema and inflammation induced by injurious ventilation. Nonetheless, this 'one-hit' model has inherent limitations. Specifically, a very high, not clinically relevant tidal volume has to be used. We and others have shown $[33,52,53]$ that only such high volume can result in distortion of lung units required to induce VILI in healthy mice. Yet, it is now clear that in patients with ARDS some alveoli are exposed to such high distending pressures [54]. Additionally, to compensate for the hemodynamic effects of high intrathoracic pressures, mice receive fluid loading, that may contribute to the development of pulmonary edema. As all groups of ventilated mice received the same amount of fluids, but only the group of WT mice ventilated on high tidal volume developed significant edema, it is reasonable to assume that fluid loading may only exacerbate the high tidal volume-induced alteration in alveolar permeability.

\section{Conclusion}

In conclusion, $\mathrm{Tpl} 2$ contributes to the pathogenesis of high-permeability pulmonary edema and inflammation induced by high tidal volume ventilation, as genetic deficiency of Tpl2 appears to be protective in this model of murine VILI. Additionally, pharmacologic inhibition of Tpl2 is effective in ameliorating indices of VILI, even when given after establishing injurious ventilation, suggesting a potential therapeutic role for Tpl2 inhibitors in VILI. 


\begin{abstract}
Abbreviations
ALl: acute lung injury; BALF: bronchoalveolar lavage; ERK1/2: extracellular signal-regulated kinase 1/2; GPCR: G proteincoupled receptors; IL-6: interleukin-6; JNK: C-Jun N-terminal kinase; MAPK: mitogen-activated serine/threonine kinase; MEK1/2 (or MAP2K): mitogen-activated protein kinase kinase; MAP3K: mitogen-activated protein kinase kinase kinase; MIP-2: macrophage inflammatory protein 2; PIP: peak inspiratory pressure; Tpl2: tumor progression locus 2; $\mathrm{Tpl}^{-/}{ }^{-1}$ : Tpl2 deficient; VILI: ventilator-induced lung injury; VT: tidal volume; WT: wild-type.
\end{abstract}

\title{
Competing interests
}

The authors of this study have no competing interests to declare.

\section{Authors' contributions}

E Kaniaris performed in vivo and in vitro experiments and drafted the manuscript, KV conceived the study, performed in vivo experiments, analyzed data, drafted, and edited the manuscript. EV and ET performed and analyzed in vitro experiments. E Kondili contributed to study design and edited the manuscript; EL performed and evaluated the histology. CT contributed to the study design, and data analysis and drafted the manuscript. DG contributed to the study design and coordination and edited the manuscript. All authors read and approved the final manuscript.

\section{Authors' information}

E Kaniaris, MD, is a fellow in pulmonary medicine and graduate student at the Department of Intensive Care Medicine, Experimental Intensive Care Medicine Laboratory, KV, MD, PhD, is an assistant professor in Intensive Care Medicine, $\mathrm{Pl}$ at the Experimental Intensive Care Medicine Laboratory, EV, MD, is a fellow in pediatrics and graduate student at the department of Clinical Chemistry, ET, MD, is a graduate student at the Department of Intensive Care Medicine. E Kondili, MD, PhD, is an assistant professor in the Department of Intensive Care Medicine; EL, MD, is a pathologist at the Department of Pathology. CT, PhD, is associate professor in Clinical Chemistry, head of the Laboratory of Clinical Chemistry, and member of the research team who generated the Tpl2-deficient mice, and DG, MD, PhD, is a professor and head of the Department of Intensive Care Medicine. All departments and authors are affiliated to the Medical School of the University of Crete in Greece.

\section{Acknowledgements}

This study has been supported by the Cretan Society for Research in Intensive Care Medicine.

\section{Author details}

${ }^{1}$ Department of Intensive Care Medicine, Experimental Intensive Care Medicine Laboratory, University of Crete, School of Medicine, Heraklio, Crete 71003, Greece. '2Department of Pathology, University of Crete, School of Medicine, Heraklio, Crete 70013, Greece. ${ }^{3}$ Department of Clinical Chemistry, University of Crete, School of Medicine, Heraklio, Crete 71003, Greece.

Received: 5 December 2013 Accepted: 26 March 2014

Published: 9 May 2014

\section{References}

1. Lionetti V, Recchia FA, Ranieri VM (2005) Overview of ventilator-induced lung injury mechanisms. Curr Opin Crit Care 11:82-86

2. Fu PF, Murley JS, Grdina DJ, Birukova AA, Birukov KG (2011) Induction of cellular antioxidant defense by amifostine improves ventilator-induced lung injury. Crit Care Med 39:2711-2721

3. Wolfson RK, Mapes B, Garcia JG (2014) Excessive mechanical stress increases HMGB1 expression in human lung microvascular endothelial cells via STAT3. Microvasc Res 92:50-55

4. Oudin S, Pugin J (2002) Role of MAP kinase activation in interleukin-8 production by human BEAS-2B bronchial epithelial cells submitted to cyclic stretch. Am J Respir Cell Mol Biol 27:107-114

5. Iwaki M, Ito S, Morioka M, Iwata S, Numaguchi Y, Ishii M, Kondo M, Kume H, Naruse K, Sokabe M, Hasegawa Y (2009) Mechanical stretch enhances IL-8 production in pulmonary microvascular endothelial cells. Biochem Biophys Res Commun 389:531-536

6. Wu JB, Yan ZB, Schwartz DE, YU JG, Malik AB, Hu GC (2013) Activation of NLRP3 inflammasome in alveolar macrophages contributes to mechanical stretch-induced lung inflammation and injury. J Immunol 190:3590-3599

7. Uhlig U, Fehrenbach H, Lachmann RA, Goldmann T, Lachmann B, Vollmer E, Uhlig S (2004) Phosphoinositide 3-OH kinase inhibition prevents ventilation-induced lung cell activation. Am J Respir Crit Care Med 169:201-208

8. Frank JA, Wray CM, McAuley DF, Schwendener R, Matthay MA (2006) Alveolar macrophages contribute to alveolar barrier dysfunction in ventilator-induced lung injury. Am J Physiol Lung Cell Mol Physiol 291:L1191-L1198

9. Johnson GL, Lapadat R (2002) Mitogen-activated protein kinase pathways mediated by ERK, JNK, and p38 protein kinases. Science 298:1911-1912

10. Lawrence MC, Jivan A, Shao C, Duan L, Goad D, Zaganjor E, Osborne J, McGlynn K, Stippec S, Earnest S, Chen W, Cobb MH (2008) The roles of MAPKs in disease. Cell Res 18:436-442

11. Liu M, Tanswell AK, Post M (1999) Mechanical force-induced signal transduction in lung cells. Am J Physiol 277:L667-L683

12. Chess PR, Toia L, Finkelstein JN (2000) Mechanical strain-induced proliferation and signaling in pulmonary epithelial H441 cells. Am J Physiol Lung Cell Mol Physiol 279:L43-L51

13. Ikeda M, Takei T, Mills I, Kito H, Sumpio BE (1999) Extracellular signal-regulated kinases 1 and 2 activation in endothelial cells exposed to cyclic strain. Am J Physiol 276:H614-H622

14. Correa-Meyer E, Pesce L, Guerrero C, Sznajder II (2002) Cyclic stretch activates ERK1/2 via G proteins and EGFR in alveolar epithelial cells. Am J Physiol Lung Cell Mol Physiol 282:L883-L891

15. Li LF, Liao SK, Huang CC, Hung MJ, Quinn DA (2008) Serine/threonine kinase-protein kinase B and extracellular signal-regulated kinase regulate ventilator-induced pulmonary fibrosis after bleomycin-induced acute lung injury: a prospective, controlled animal experiment. Crit Care 12:R103 
16. Roberts PJ, Der CJ (2007) Targeting the Raf-MEK-ERK mitogen-activated protein kinase cascade for the treatment of cancer. Oncogene 26:3291-3310

17. Morris EJ, Jha S, Restaino CR, Dayananth P, Zhu H, Cooper A, Carr D, Deng YG, Jin WH, Black S, Long B, Liu J, DiNunzio E, Windsor W, Zhang RM, Zhao SX, Angagaw MH, Pinheiro EM, Desai J, Xiao L, Shipps G, Hruza A, Wang J, Kelly J, Paliwal S, Gao XL, Babu BS, Zhu L, Daublain P, Zhang L, Lutterbach BA, Pelletier MR, Philippar U, Siliphaivanh P, Witter D, Kirschmeier P, Bishop WR, Hicklin D, Gilliland DG, Jayaraman L, Zawel L, Fawell S, Samatar AA (2013) Discovery of a novel ERK inhibitor with activity in models of acquired resistance to BRAF and MEK inhibitors. Canc Discov 3:742-750

18. Lindstrom TM, Robinson WH (2010) A multitude of kinases-which are the best targets in treating rheumatoid arthritis? Rheum Dis Clin N Am 36:367-383

19. Sawalha AH, Richardson B (2008) MEK/ERK pathway inhibitors as a treatment for inflammatory arthritis might result in the development of lupus: comment on the article by Thiel et al. Arthritis Rheum 58:1203-1204. author reply 1204

20. Salmeron A, Ahmad TB, Carlile GW, Pappin D, Narsimhan RP, Ley SC (1996) Activation of MEK-1 and SEK-1 by Tpl-2 proto-oncoprotein, a novel MAP kinase kinase kinase. EMBO J 15:817-826

21. Ceci JD, Patriotis CP, Tsatsanis C, Makris AM, Kovatch R, Swing DA, Jenkins NA, Tsichlis PN, Copeland NG (1997) Tpl-2 is an oncogenic kinase that is activated by carboxy-terminal truncation. Genes Dev 11:688-700

22. Vougioukalaki M, Kanellis DC, Gkouskou K, Eliopoulos AG (2011) Tpl2 kinase signal transduction in inflammation and cancer. Cancer Lett 304:80-89

23. Tsatsanis C, Patriotis C, Tsichlis PN (1998) Tpl-2 induces IL-2 expression in T-cell lines by triggering multiple signaling pathways that activate NFAT and NF-kappaB. Oncogene 17:2609-2618

24. Tsatsanis C, Patriotis C, Bear SE, Tsichlis PN (1998) The Tpl-2 protooncoprotein activates the nuclear factor of activated T cells and induces interleukin 2 expression in T cell lines. Proc Natl Acad Sci U S A 95:3827-3832

25. Tsatsanis C, Vaporidi K, Zacharioudaki V, Androulidaki A, Sykulev Y, Margioris AN, Tsichlis PN (2008) Tpl2 and ERK transduce antiproliferative T cell receptor signals and inhibit transformation of chronically stimulated T cells. Proc Natl Acad Sci U S A 105:2987-2992

26. Christoforidou AV, Papadaki HA, Margioris AN, Eliopoulos GD, Tsatsanis C (2004) Expression of the Tpl2/Cot oncogene in human T-cell neoplasias. Mol Cancer 3:34

27. Patriotis C, Makris A, Chernoff J, Tsichlis PN (1994) Tpl-2 acts in concert with Ras and Raf-1 to activate mitogenactivated protein kinase. Proc Natl Acad Sci U S A 91:9755-9759

28. Dumitru CD, Ceci JD, Tsatsanis C, Kontoyiannis D, Stamatakis K, Lin JH, Patriotis C, Jenkins NA, Copeland NG, Kollias G, Tsichlis PN (2000) TNF-alpha induction by LPS is regulated posttranscriptionally via a Tpl2/ERK-dependent pathway. Cell 103:1071-1083

29. Eliopoulos AG, Dumitru CD, Wang CC, Cho J, Tsichlis PN (2002) Induction of COX-2 by LPS in macrophages is regulated by Tpl2-dependent CREB activation signals. EMBO I 21:4831-4840

30. Hatziapostolou M, Polytarchou C, Panutsopulos D, Covic L, Tsichlis PN (2008) Proteinase-activated receptor-1triggered activation of tumor progression locus-2 promotes actin cytoskeleton reorganization and cell migration. Cancer Res 68:1851-1861

31. Van Acker GJ, Perides G, Weiss ER, Das S, Tsichlis PN, Steer ML (2007) Tumor progression locus-2 is a critical regulator of pancreatic and lung inflammation during acute pancreatitis. J Biol Chem 282:22140-22149

32. Lawrenz M, Visekruna A, Kuhl A, Schmidt N, Kaufmann SHE, Steinhoff U (2012) Genetic and pharmacological targeting of TPL-2 kinase ameliorates experimental colitis: a potential target for the treatment of Crohn's disease. Mucosal Immunol 5:129-139

33. Vaporidi K, Vergadi E, Kaniaris E, Hatziapostolou M, Lagoudaki E, Georgopoulos D, Zapol WM, Bloch KD, lliopoulos D (2012) Pulmonary microRNA profiling in a mouse model of ventilator-induced lung injury. Am J Physiol Lung Cell Mol Physiol 303:L199-L207

34. Kaila N, Green N, Li HQ, Hu Y, Janz K, Gavrin LK, Thomason J, Tam S, Powell D, Cuozzo J, Hall JP, Telliez JB, Hsu S, Nickerson-Nutter C, Wang Q, Lin LL (2007) Identification of a novel class of selective Tpl2 kinase inhibitors: 4-alkylamino-[1,7]naphthyridine-3-carbonitriles. Bioorg Med Chem 15:6425-6442

35. Matute-Bello G, Downey G, Moore BB, Groshong SD, Matthay MA, Slutsky AS, Kuebler WM, Grp ALIAS (2011) An official American Thoracic Society workshop report: features and measurements of experimental acute lung injury in animals. Am J Respir Cell Mol Biol 44:725-738

36. Stuber F, Wrigge H, Schroeder S, Wetegrove S, Zinserling J, Hoeft A, Putensen C (2002) Kinetic and reversibility of mechanical ventilation-associated pulmonary and systemic inflammatory response in patients with acute lung injury. Intensive Care Med 28:834-841

37. Sanz-Garcia C, Ferrer-Mayorga G, Gonzalez-Rodriguez A, Valverde AM, Martin-Duce A, Velasco-Martin JP, Regadera J, Fernandez M, Alemany S (2013) Sterile inflammation in acetaminophen-induced liver injury is mediated by Cot/ Tpl2. J Biol Chem 288:15342-15351

38. Perfield JW, Lee Y, Shulman GI, Samuel VT, Jurczak MJ, Chang E, Xie C, Tsichlis PN, Obin MS, Greenberg AS (2011) Tumor progression locus 2 (TPL2) regulates obesity-associated inflammation and insulin resistance. Diabetes 60:1168-1176

39. Carter CA, Misra M, Pelech S (2011) Proteomic analyses of lung lysates from short-term exposure of Fischer 344 rats to cigarette smoke. J Proteome Res 10:3720-3731

40. Hausenloy DJ, Yellon DM (2007) Reperfusion injury salvage kinase signalling: taking a RISK for cardioprotection. Heart Fail Rev 12:217-234

41. Sawe N, Steinberg G, Zhao H (2008) Dual roles of the MAPK/ERK1/2 cell signaling pathway after stroke. J Neurosci Res 86:1659-1669

42. Hall JP, Kurdi Y, Hsu S, Cuozzo J, Liu J, Telliez JB, Seidl KJ, Winkler A, Hu Y, Green N, Askew GR, Tam S, Clark JD, Lin LL (2007) Pharmacologic inhibition of Tpl2 blocks inflammatory responses in primary human monocytes, synoviocytes, and blood. J Biol Chem 282:33295-33304

43. Hu YH, Cole D, Denny RA, Anderson DR, Ipek M, Ni YK, Wang XL, Thaisrivongs S, Chamberlain T, Hall JP, Liu J, Luong M, Lin LL, Telliez JB, Gopalsamy A (2011) Discovery of indazoles as inhibitors of Tpl2 kinase. Bioorg Med Chem Lett 21:4758-4761 
44. Ni YK, Gopalsamy A, Cole D, Hu YH, Denny R, Ipek M, Liu J, Lee J, Hall JP, Luong M, Telliez JB, Lin LL (2011) Identification and SAR of a new series of thieno[3,2-d]pyrimidines as Tpl2 kinase inhibitors. Bioorg Med Chem Lett 21:5952-5956

45. Robert C, Dummer R, Gutzmer R, Lorigan P, Kim KB, Nyakas M, Arance A, Liszkay G, Schadendorf D, Cantarini M, Spencer S, Middleton MR (2013) Selumetinib plus dacarbazine versus placebo plus dacarbazine as first-line treatment for BRAF-mutant metastatic melanoma: a phase 2 double-blind randomised study. Lancet Oncol 14:733-740

46. Cohen RB, Aamdal S, Nyakas M, Cavallin M, Green D, Learoyd M, Smith I, Kurzrock R (2013) A phase I dose-finding, safety and tolerability study of AZD8330 in patients with advanced malignancies. Eur J Cancer 49:1521-1529

47. Farley J, Brady WE, Vathipadiekal V, Lankes HA, Coleman R, Morgan MA, Mannel R, Yamada SD, Mutch D, Rodgers WH, Birrer M, Gershenson DM (2013) Selumetinib in women with recurrent low-grade serous carcinoma of the ovary or peritoneum: an open-label, single-arm, phase 2 study. Lancet Oncol 14:134-140

48. Kirkwood JM, Bastholt L, Robert C, Sosman J, Larkin J, Hersey P, Middleton M, Cantarini M, Zazulina V, Kemsley K, Dummer R (2012) Phase Il, open-label, randomized trial of the MEK1/2 inhibitor selumetinib as monotherapy versus temozolomide in patients with advanced melanoma. Clin Cancer Res 18:555-567

49. Bandow K, Kusuyama J, Shamoto M, Kakimoto K, Ohnishi T, Matsuguchi T (2012) LPS-induced chemokine expression in both MyD88-dependent and-independent manners is regulated by Cot/Tpl2-ERK axis in macrophages. FEBS Lett 586:1540-1546

50. Mielke LA, Elkins KL, Wei L, Starr R, Tsichlis PN, O'Shea JJ, Watford WT (2009) Tumor progression locus 2 (Map3k8) is critical for host defense against Listeria monocytogenes and IL-1 beta production. J Immunol 183:7984-7993

51. Watford WT, Hissong BD, Durant LR, Yamane H, Muul LM, Kanno Y, Tato CM, Ramos HL, Berger AE, Mielke L, Pesu M, Solomon B, Frucht DM, Paul WE, Sher A, Jankovic D, Tsichlis PN, O'Shea JJ (2008) Tpl2 kinase regulates T cell interferon-gamma production and host resistance to Toxoplasma gondii. J Exp Med 205:2803-2812

52. Wilson MR, Patel BV, Takata M (2012) Ventilation with "clinically relevant" high tidal volumes does not promote stretch-induced injury in the lungs of healthy mice. Crit Care Med 40:2850-2857

53. Protti A, Cressoni M, Santini A, Langer T, Mietto C, Febres D, Chierichetti M, Coppola S, Conte G, Gatti S, Leopardi O, Masson S, Lombardi L, Lazzerini M, Rampoldi E, Cadringher P, Gattinoni L (2011) Lung stress and strain during mechanical ventilation: any safe threshold? Am J Respir Crit Care Med 183:1354-1362

54. Gattinoni L, Carlesso E, Caironi P (2012) Stress and strain within the lung. Curr Opin Crit Care 18:42-47

doi:10.1186/2197-425X-2-15

Cite this article as: Kaniaris et al:: Genetic and pharmacologic inhibition of Tpl2 kinase is protective in a mouse model of ventilator-induced lung injury. Intensive Care Medicine Experimental 2014 2:15.

Submit your manuscript to a SpringerOpen ${ }^{\odot}$ journal and benefit from:

- Convenient online submission

Rigorous peer review

- Immediate publication on acceptance

- Open access: articles freely available online

High visibility within the field

- Retaining the copyright to your article

Submit your next manuscript at $\boldsymbol{\sim}$ springeropen.com 